\title{
A comparative study on socio-demographic profile, working environment and morbidity profile among shoemakers and non shoemakers in a slum area of Kolkata.
}

\author{
Dr MD Samsuzzaman ${ }^{1}$, Dr Prasanta Kumar Bhattacharyya ${ }^{2}$, \\ Dr Nirmalya Manna ${ }^{1}$, Dr Saikat Das ${ }^{1}$ \\ ${ }^{I}$ Department of Community Medicine, Medical College Kolkata \\ ${ }^{2}$ Department of Plastic Surgery, KPC Medical College \\ Corresponding author: Dr MD Samsuzzaman \\ 6 Alimuddin street, Flat no 2, $1^{\text {st }}$ floor, Kolkata - 700016
}

\begin{abstract}
Shoemakers and their health have attracted less attention than the shoes themselves. An observational descriptive study with community based cross sectional design was undertaken at slum area of urban field practice area of Medical College, Kolkata for total duration of 6 months. 160 shoemakers from 34 workshops were taken and compared with 112 non shoemakers from 34 families were interviewed and examined. Eyestrain, peripheral neuropathy, musculo-skeletal symptoms were more prevalent among shoemakers. Appropriate advice was given regarding their health condition.
\end{abstract}

Key words: Shoemakers, Workshops, Eyestrain

\section{Introduction}

Shoes have played an important role in human culture throughout history. Shoemakers and their health, however, have attracted less attention than the shoes themselves. Mass production in the shoe industry started in the late $1850^{\prime} \mathrm{s}^{1}$; however, changes in production methods did not improve poor working conditions and related occupational health problems among shoemakers, particularly in less developed countries ${ }^{2}$. Indian urban areas, where a number of elite people enjoy classic life comfortably \& simultaneous there is also co-existing of a few group who are socially, mentally, economically, politically and culturally backward and the touch of development they cannot receive properly ${ }^{1}$. The research paper highlighted morbidity status of such a group of working people who are engaged in making various kind of shoes in a slum area of Kolkata.

Steps of shoe making and associated health hazards ${ }^{3,4}$ :

\begin{tabular}{|c|c|}
\hline Steps & Associated health hazards \\
\hline 1. Measuring & - $\quad$ Eye strain (due to poor illumination) $)^{5}$ \\
\hline $\begin{array}{l}\text { 2. Last making ( Lasts are made up of wood or } \\
\text { plastic) }\end{array}$ & $\begin{array}{l}\text { - Exposure to wood or plastic dusts - nasopharyngeal } \\
\text { cancer }\end{array}$ \\
\hline $\begin{array}{l}\text { 3. Pattern cutting/clicking (Desired pattern is selected } \\
\text { and leather is cut with a special scissor) }\end{array}$ & $\begin{array}{l}\text { - } \quad \text { Exposure to leather dust } \\
\text { - Injury }\end{array}$ \\
\hline 4. Sole cutting & $\begin{array}{ll}\text { - } & \text { Injury } \\
\text { - } & \text { Exposure to wood or plastic dusts }\end{array}$ \\
\hline 5. Closing, assembling and sewing & $\begin{array}{l}\text { - } \\
\text { - Exposure to chemicals in adhesives } \\
\text { tertiary butyl phenols) and glues (benzene is used as a } \\
\text { solvent for glues) }\end{array}$ \\
\hline 6. Polishing & - Exposure to chemical (Nitrate and nitrite) \\
\hline 7. Making boxes & Eye strain \\
\hline
\end{tabular}

Various risk factors including leather dust, petroleum products, metals and solvents-deteriorate shoemakers' health. Other studies report chemical exposures, noise, vibration, stress and ergonomic problems as main causes of health problems, which includes ${ }^{5}$ musculoskeletal disorder (specially low back pain), Skin ailment(contact dermatitis, occupational vitiligo due to contact with benzene and para-tertiary butyl phenol in glues and adhesives), Neuropsychiatric disorders ( peripheral neuropathy, carpal tunnel syndrome, depression), Occupational cancer(carcinoma of nose and paranasal sinuses, malignant neoplasm of larynx and lung in males and gallbladder and lung in females), Occupational injury, Communicable diseases like scabies and tuberculosis due to poor work environment, Non communicable diseases like Hypertension and Diabetes, Others like eyestrain, headache, stress etc. In this cross-sectional study, the main aim was to investigate the sociodemographic profile, working environment, morbidity status of shoemakers in different age groups, including child workers in an urban slum area of Kolkata, West Bengal and to compare the above factors with the 
populations those are not associated with shoemaking. The study have following objectives - to know the socio-demographic profile among the shoemakers, to explore the working environment of the shoemakers who are living and working in that area, to study the morbidity profile of the shoemakers and to compare the above factors with non shoemakers.

\section{Methodology}

It was an descriptive observational study with community based cross sectional design done at slum area of ward no 37, borough V (Urban field practice area of Medical College, Kolkata) for total duration of 6 month (August 2013 to January 2014). In a study it has been found that prevalence of chronic respiratory symptoms among shoe makers was $39.5 \%{ }^{6}$. So $\mathrm{p}=39.5 \%$ and $\mathrm{q}=60.5$. Taking $95 \%$ confidence interval \& $20 \%$ allowable relative error, sample size becomes 152 . Taking $10 \%$ more for necessary exclusions and non response the final sample size $=152+15=167$ (approximately). From line listing done it has been found that there are 341 workshops with 2056 workers (on an average $4-6$ people/workshop). Randomly selected 34 workshops ( $10 \%$ of total workshops) were visited during the schedule time period to obtain desired sample size. Total sample size was 160. Randomly selected 34 families from the study area were selected as comparison group in which none of the family members have never worked or exposed to or associated with shoemaking. Total no of family members were 112. Total period of data collection was 4 month. Going to the field twice a week, yielded 34 working day. In each day all the shoemaker in one workshop and all the family members of one family were interviewed through predesigned pretested schedule followed by physical examination and investigations. Data thus collected was compiled and analysed by SPSS (version 20). Those who are working and living in that area, those who are not seriously ill, those who were present on the date of visit were included in the study. Pre-designed pre-tested schedule, Sphygmomanometer, Stethoscope, Measuring tape, Weighing machine and Wright's mini peak flow meter were used as a tools and Interviewing, Blood pressure recording, Clinical examination, Anthropometric measurement and Measurement of PEFR were the techniques for data collection.Study subjects were informed about the study and interviewed after taking written consent. No harm to the participants was guaranteed. If any morbidity is detected appropriate advice was given. Anonymity and confidentiality was maintained.

\section{Results}

Majority of the study population belonged to age group of $15-29$ years (35\%) while in comparison group it was less than 15 years (39.29\%). 85\% were male. $66.88 \%$ were Hindu, and $60 \%$ were just literate in study population while in comparison group these were $69.64 \%, 62.50 \%$ and $38.39 \%$ respectively. Average per capita income (monthly) was higher (Rs 3430) in shoemakers than non shoemakers (Rs 2280). 79.41\% workshops were pucca while $88.24 \%$ families were pucca type. Average no of person living per workshop and families were 4.70 and 3.29 respectively. Mean floor area (in sq.ft) and mean per capita floor area (in sq.ft) in workshops were $83.12 \pm 16.43$ and $24.66 \pm 6.83$ respectively while those in families were $72.54 \pm 18.90$ and $26.20 \pm 8.84$ respectively. Overcrowding was observed in $94.11 \%$ workshops and $82.35 \%$ families according to floor space criteria. Ventilation was adequate, cross ventilation was present, lighting was adequate and dampness was present in $11.76 \%, 20.58 \%, 23.52 \%$ and $76.47 \%$ workshops and $26.47 \%, 29.41 \%, 29.41 \%$ and $64.70 \%$ respectively. Majority of shoemakers $(50 \%)$ are involved in Last making step. All the shoemakers are involved in multiple steps. Majority of shoemakers (33.13\%) are involved in shoemaking for $6-10$ years and $81.87 \%$ are working more than 12 hour per day. Average Duration of present work (in years) is 12.35 years. Mean daily duration of work (in hours) 11.34 \pm 2.07 . Most common form of addiction among shoemakers is smokeless tobacco $(48.75 \%)$. Prevalence of hypertension is more in comparison group $(13.39 \%)$ than in study population $(10.63 \%)$. The difference in proportion is statistically insignificant $(Z=0.68 ; p>0.05)$. Prevalence of pallor is slightly more in comparison group $(8.92 \%)$ than study population $(8.75 \%)$. This difference in proportion is also statistically insignificant $(\mathrm{Z}=0.48 ; \mathrm{p}>0.05)$. Higher prevalence of eyestrain $(30.63 \%)$ was found in study population than that of comparison group $(4.46 \%)$. This difference is statistically significant $(\mathrm{p}<0.05 ; \mathrm{Z}=6.33)$. Highest percentage of symptom is burning sensation of eye $(48.98 \%)$. Higher prevalence of peripheral neuropathy $(20.63 \%)$ was found in study population than that of comparison group $(9.82 \%)$. This difference is statistically significant $(\mathrm{p}<0.05)$. Study populations who were complaining of peripheral neuropathy, majority (54.54\%) had symptoms numbness and tingling over hand and / feet. Higher prevalence of musculo skeletal symptoms (38.75\%) was found in study population than that of comparison group $(20.26 \%)$. This difference is statistically significant $(\mathrm{p}<0.05)$. Majority of study population $(61.29 \%)$ had symptom of pain in lower back. Lower prevalence of skin symptoms (13.75\%) was found in study population than that of comparison group (25\%). Those complaining about skin symptoms, $72.27 \%$ had complaint of generalised pruritus. Higher prevalence of respiratory symptoms $(36.25 \%)$ was found in study population than that of comparison group $(14.29 \%)$. This difference is statistically significant $(\mathrm{p}<0.05)$. Mean PEFR value is lower in

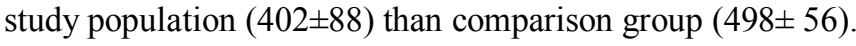




\section{Discussion}

A community based cross sectional study was carried out in order to study the socio-demographic profile, working environment, morbidity status and health seeking behaviour of shoemakers and to compare the above factors with non shoemakers. Average monthly per capita income is higher among shoemakers (Rs 3430) than the comparison group (Rs 2280). This is one of the probable reasons why large numbers of peoples are engaged in shoemaking. Majority of the shoemakers as well as the comparison group live in poor ventilated, overcrowded, damp, pucca house with inadequate lighting, poor illumination and without cross ventilation. These living conditions might be associated with communicable disease, eyestrain, respiratory morbidity in the shoemakers. Which are discussed later. Majority of shoemakers (50\%) are involved in Last making step. Almost all the shoemakers are involved in multiple steps. Average Duration of present work (in years) is 12.35 years. Mean daily duration of work (in hours) 11.34 \pm 2.07 . Prevalence of hypertension is more in comparison group $(13.39 \%)$ than in study population $(10.63 \%)$. The difference in proportion is statistically insignificant $(\mathrm{Z}=0.68$; $\mathrm{p}>0.05)$. Prevalence of pallor is slightly more in comparison group $(8.92 \%)$ than study population $(8.75 \%)$. This difference in proportion is also statistically insignificant $(Z=0.48 ; p>0.05)$. The prevalence of eyestrain among the shoemakers was found to be $30.63 \%$ while that among comparison group was much lower $4.46 \%$. This difference is statistically significant $(\mathrm{p}<0.05 ; \mathrm{Z}=6.33)$. The high prevalence can partly be attributed to the cumulative exposure to the poor illumination and solvent fumes causing strain on eyes. Similar study showed prevalence of eyestrain in the working children of footwear industry was found to be $25.9 \%{ }^{5}$. The suggested causes of eyestrain include fatigue of ciliary and extra ocular muscles. and dryness of eyes. Irritating effects of fumes coming out from adhesive solutions could also result in lacrimation and irritation of eyes. These adhesives contain a mixture of organic solvents such as hexane, benzene, propane, dimethyl heptane, cyclohexane, xylene,cyclopentane. Most common symptoms of asthenopia is burning sensation (48.98\%) and most prevalent in age group under 15 years. Risk factors included age less than 15 years male sex, inadequate lighting, poor illumination, employment duration $\geq 12$ years and daily duration of work $\geq 12$ hours. Higher prevalence of peripheral neuropathy $(20.63 \%)$ was found in study population than that of comparison group $(9.82 \%)$. This difference is statistically significant $(\mathrm{p}<0.05)$. M.C symptom is numbness and tingling over hand and / feet. Similar study showed prevalence of peripheral neuropathy among 318 worker was $27.8 \%$ and Hexane - 2,5 -dione is an important metabolite in urine was found to be associated with peripheral neuropathy ${ }^{2}$. However $33.13 \%$ population were alcoholic therefore, alcohol could be additional triggering factor for peripheral neuropathy. Higher prevalence of musculo skeletal symptoms $(38.75 \%)$ was found in study population than that of comparison group $(20.26 \%)$. This difference is statistically significant $(\mathrm{p}<0.05)$. Majority $(61.29 \%)$ had symptom of pain in lower back. These symptoms may be continuous sitting postural habit. Lower prevalence of skin symptoms $(13.75 \%)$ was found in study population than that of comparison group $(25 \%)$. $72.27 \%$ had complaint of generalised pruritus. Overcrowding, poor ventilation of working environment as well as exposure to dust and/or chemical may be the causative factor. Higher prevalence of respiratory symptoms $(36.25 \%)$ was found in study population than that of comparison group (14.29\%). This difference is statistically significant $(p<0.05)$. Mean PEFR value is lower in study population suggests that they are exposed to dusts and chemicals which causes obstruction in airflow.

\section{Conclusion}

A community based cross sectional study was carried out in order to study the socio-demographic profile, working environment, morbidity status and health seeking behaviour of shoemakers and to compare the above factors with non shoemakers. The study aimed to initiate an effort; much more in-depth research work on morbidity profile among shoemakers required for proper management and subsequent remedial steps can be taken accordingly.

\section{References}

[1]. Pal Tapas. Geography of urban cobblers(muchi or shoemakers) : an overview in Bolpur town, West Bengal, India. Indian journal of business and social science (internet, cited on $10^{\text {th }}$ February, 2013). 2011, January. 2(3): 238-45. Available from www.ijbssnet.com

[2]. Elci OC et al. Working conditions and related neuropsychiatric problems among shoemakers in Turkey: Do child workers differ from others?. Indian Journal of Occupational and Environmental medicine. (internet, 2007, cited on February 12 ${ }^{\text {th }}$, 2013)];11:9-14. Available from: http://www.ijoem.com/text.asp

[3]. Tiwari Rajnarayan R. Child labour in footwear industry: possible occupational health hazards. Indian journal of occupational and environmental medicine (internet, cited on 10 ${ }^{\text {th }}$ February, 2013) 2005,April: 9(1): 7-9. Available from : http://www.ijoem.com/text.asp

[4]. Gangopadhya et al. An occupational health study of the footwear manufacturing worker of Kolkata. Ethnomed(internet, cited on 10 $0^{\text {th }}$ February, 2013). 2011: 5(1):11-15

[5]. Tiwari Rajnarayan R. Eyestrain in working children of footwear making units of Agra, India. Indian paediatrics. October 5, 2012. (internet, cited on $10^{\text {th }}$ February, 2013), 1-9, pdf.

[6]. Abdallah Heba Mahdy et al. Ventilatory function and oxidative-antioxidant status in shoemakers. Sciencepub.net. 2010 (internet, cited on $18^{\text {th }}$ February) 2010:2(4).59-66 


\section{Charts and tables}

Table no - 1: Comparison of workshops and families according to the housing and environmental condition

\begin{tabular}{|l|c|c|}
\hline \multicolumn{1}{|c|}{ Housing and environmental condition } & Workshop $(\mathrm{n}=34)$ & Families $(\mathrm{n}=34)$ \\
\hline $\begin{array}{l}\text { Type of house } \\
\bullet \quad \text { Pucca }\end{array}$ & $27(79.41 \%)$ & $30(88.24 \%)$ \\
& $7(20.59 \%)$ & $41.76 \%)$ \\
\hline $\begin{array}{l}\text { Average no of person living per workshop or } \\
\text { families }\end{array}$ & 4.70 & 3.29 \\
\hline Mean floor area (sq.ft) \pm S.D & $83.12 \pm 16.43$ & $72.54 \pm 18.90$ \\
\hline Mean per capita floor area ( sq.ft) \pm S.D & $24.66 \pm 6.83$ & $26.20 \pm 8.84$ \\
\hline $\begin{array}{l}\text { Presence of overcrowding } \\
\text { (According to per capita floor space) }\end{array}$ & $32(94.11 \%)$ & $28(82.35 \%)$ \\
\hline Adequate ventilation & $4(11.76 \%)$ & $9(26.47 \%)$ \\
\hline Presence of cross ventilation & $7(20.58 \%)$ & $10(29.41 \%)$ \\
\hline Lighting adequate & $8(23.52 \%)$ & $10(29.41 \%)$ \\
\hline $\begin{array}{l}\text { Illumination of artificial light (by observation) is } \\
\text { good }\end{array}$ & $13(38.24 \%)$ & $17(50 \%)$ \\
\hline Dampness present & $26(76.47 \%)$ & $22(64.70 \%)$ \\
\hline
\end{tabular}

Table no - 2: Comparison of morbidities among shoemakers and non shoemakers

\begin{tabular}{|l|c|c|}
\hline Morbidities & $\begin{array}{l}\text { Prevalence among } \\
\text { shoemakers (\%) }\end{array}$ & $\begin{array}{l}\text { Prevalence among } \\
\text { non shoemakers (\%) }\end{array}$ \\
\hline Hypertension & 10.63 & 13.39 \\
\hline Pallor & 8.92 & 8.75 \\
\hline Eyestrain & 30.63 & 4.46 \\
\hline Peripheral neuropathy & 20.63 & 9.82 \\
\hline Masculo skeletal symptoms & 38.75 & 20.26 \\
\hline Skin ailments & 13.75 & 25.00 \\
\hline Respiratory symptoms & 36.25 & 14.29 \\
\hline
\end{tabular}

